\title{
Silica-Titania Films Fabricated by Sol-Gel Method for Applications in Planar Photonics
}

\author{
P. KARASIŃSKI* \\ Optoelectronics Department, Silesian University of Technology, B. Krzywoustego 2, 44-100 Gliwice, Poland \\ The work presents silica films produced with sol-gel method of extremely different refractive indices as well \\ as two-component waveguide films $\mathrm{SiO}_{2}: \mathrm{TiO}_{2}$ of very low attenuation.
}

PACS numbers: 42.25.Bs, 42.79.Gn, 42.79.Wc, 78.67.Rb, 81.15.Lm

\section{Introduction}

The sol-gel method is a chemical way to produce glass and ceramics from a liquid phase [1]. The basic processes involve the hydrolysis of alkoxides of respective metals or non-metals leading to the formation of sol, and the condensation, which leads to the formation of gel. Optical films for planar optics are most frequently fabricated using dip-coating or spin coating methods. The process is finished up by heating, after which the films assume their final properties. One of the principle advantages of sol-gel method is the ability to control the structure of the produced materials. From the same material we can produce films of a different structure and hence of different refractive indices.

The work presents silica films produced with sol-gel method of extremely different refractive indices as well as two-component waveguide layers $\mathrm{SiO}_{2}: \mathrm{TiO}_{2}$ of very low attenuation. We have produced silica films of the minimum refractive indices $\approx 1.2$ and two-component films of the refractive index above 1.8. The films of such refractive indices can be widely applied in planar photonics. The elaborated silica films have already been applied in sensitive film technology [2], and the two-component films are being applied as waveguide layers [3-7].

\section{Film fabrication}

The precursor of silica in the technology of the presented films was tetraethoxysilane $\mathrm{Si}\left(\mathrm{OC}_{2} \mathrm{H}_{5}\right)_{4}$ (TEOS) [2] and the precursor of titania was titanium(IV) ethoxide $\mathrm{Ti}\left(\mathrm{OC}_{2} \mathrm{H}_{5}\right)_{4}$ (TET) [3]. The films on glass substrate were fabricated using the dip-coating method. Soda-lime glass substrates and BK7 glass substrates of the dimensions $76 \times 26 \times 1 \mathrm{~mm}^{3}$ were applied. The basic parameter, which in this method determines the thickness $d$ of the fabricated film is the withdrawal rate $\nu$ of the substrate from sol. The dependence of the thickness $d$ on the withdrawal rate $\nu$ can be written using the following formula [3]:

\footnotetext{
* corresponding author; e-mail: pawel.karasinski@polsl.pl
}

$$
d=A \nu^{\alpha}+d_{0} .
$$

For a given technological process, the proportionality in$\operatorname{dex} A$ and the slope $\alpha$ can be determined empirically. The dependences of the thickness $d$ and of the refractive index $n$ of the layers on the withdrawal rate $v$ are basic technological characteristics in the dip-coating method. The thicknesses and the refractive indices of the produced films were determined with the use of a monochromatic ellipsometer Sentech SE400 (Germany). The measurements were carried out for the wavelength $\lambda=632.8 \mathrm{~nm}$.

\section{Experimental results}

\subsection{Silica films}

Figure 1 presents the dependence of the thickness $d$ and of the refractive index $n$ on the withdrawal rate of the substrate from the sol for silica films. For the sake of comparison also the refractive index level of dense silica was marked. The precursor of silica films was TEOS [8-10]. Ethyl alcohol (EtOH) was applied as the homogenizing agent and hydrochloric acid $\mathrm{HCl}$ as a catalyst. The molar ratio of the sol components was TEOS:EtOH: $\mathrm{H}_{2} \mathrm{O}: \mathrm{HCl}=$ 1:8:8:0.04. The sol formation process was carried out for $3 \mathrm{~h}$ at temperature of $50^{\circ} \mathrm{C}$ in ultrasonic field. Then the produced films were dried and heated at temperature of $500{ }^{\circ} \mathrm{C}$ for $2 \mathrm{~h}$. The average refractive index of the films is here $n=1.445$, and it is close to the value of the refractive index of dense silica. The influence of technological parameters on the properties of silica films was extensively described in previous works [8-10].

By adding a surface active agent to the sol, we can reduce the surface tension of the sol, enforce the rise of particles of polymerizing gel and decrease the inward tension. In this way we can obtain silica films of high porosity, and, in effect, of low refractive index. Such films have been recently investigated by the author [10]. The dependence of the thickness and the refractive index on the withdrawal rate of the substrate from the sol for such films is presented in Fig. 2. The films were heated for 40 min at temperature of $450{ }^{\circ} \mathrm{C}$. All refractive indices of the films are within the range from 1.221 to 1.233. Basing on the measured refractive indices $n$ we can determine 


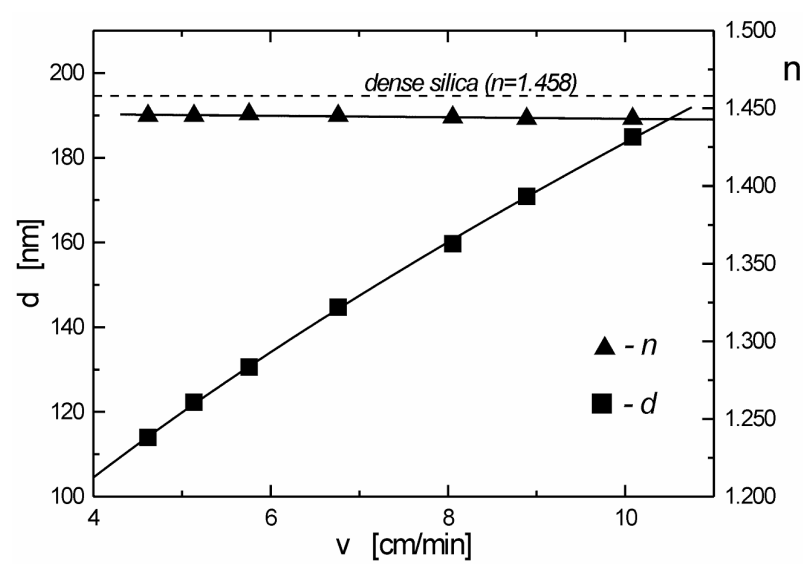

Fig. 1. Film thickness and refractive index vs. substrate withdrawal speed for silica of high refractive index.

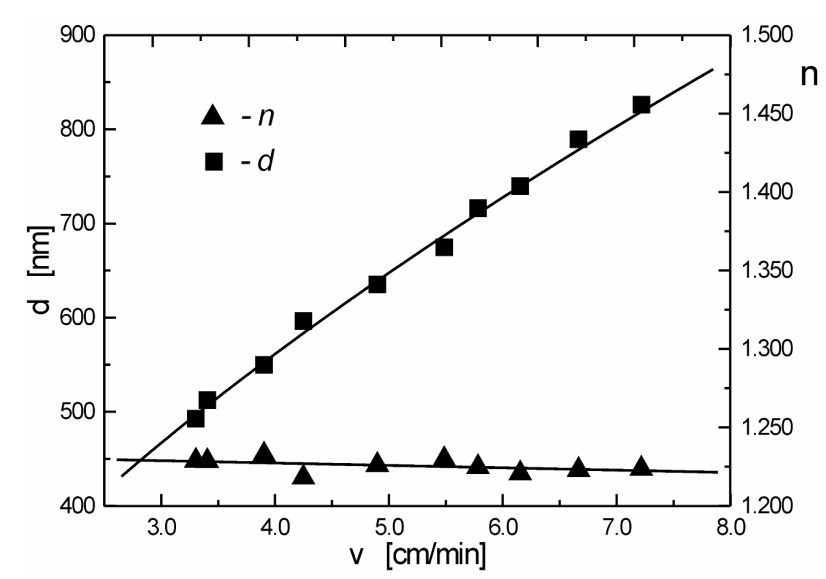

Fig. 2. Film thickness and refractive index vs. substrate withdrawal speed for porous silica.

the porosity of the films, using the Lorentz-Lorenz formula

$$
\frac{n^{2}-1}{n^{2}+2}=\left(1-\frac{P}{100 \%}\right) \frac{n_{d}^{2}-1}{n_{d}^{2}+2},
$$

where $n_{d}$ is the refractive index of dense silica equal to 1.4585. The porosity of the presented here films is from $46 \%$ to $49 \%$. The above values were determined basing on the relative humidity of $40 \%$. All of the presented here silica films were cracked free.

\subsection{Silica-titania films}

Two-component inorganic waveguide films $\mathrm{SiO}_{2}: \mathrm{TiO}_{2}$ of high refractive index were produced using TEOS and TET as precursors, respectively of silica and titania [3]. The processes of hydrolysis of TEOS and TET were introduced in two stages. Initially, the hydrolysis of each precursors was carried out separately. Then, the solutions were mixed in appropriate proportions and the process was carried out. The molar ratio of TEOS:TET was 1:1. For the final solutions $\mathrm{pH}=3$ was measured. The fabricated structures were heated for $1 \mathrm{~h}$ at temperature of $500{ }^{\circ} \mathrm{C}$. The dependences involving the thickness and refractive index on the withdrawal rate of the substrate from the sol for the obtained films are presented in Fig. 3. The average refractive index of the films is $n=1.810$.

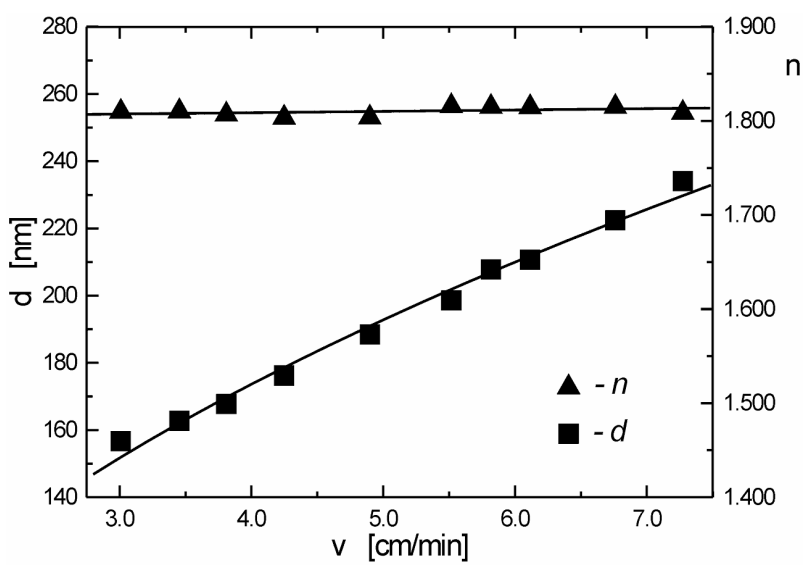

Fig. 3. Film thickness and refractive index vs. substrate withdrawal speed for silica-titania films.

All films were cracked free single-mode waveguides. For these films the attenuation measurements were carried out using the streak method. The waveguides were excited using a prism coupler. A laser diode of the wavelength $\lambda=677 \mathrm{~nm}$ was used as light source. A digital video camera (Panasonic WV-BL.730/G) was applied to register the streak in the excited planar waveguide. The attenuation was determined from the scattered light decrease along the streak. The image of the excited waveguide is presented in Fig. 4. The attenuation for the

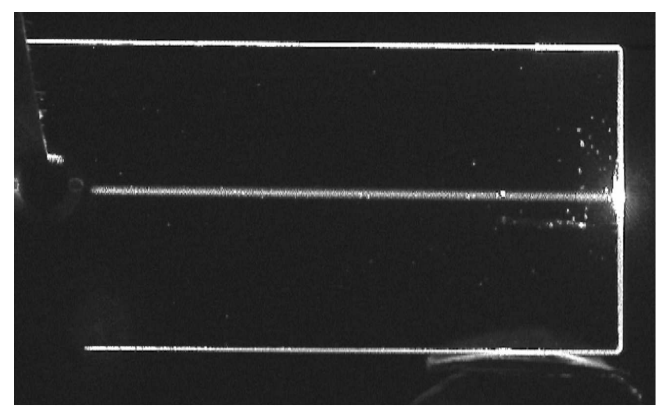

Fig. 4. Image of excited slab waveguide.

$\mathrm{TM}_{0}$ mode in the film of the thickness $d=190 \mathrm{~nm}$ was $(0.30 \pm 0.10) \mathrm{dB} / \mathrm{cm}$. For the waveguide films of such high refractive indices these attenuation values are very low. Therefore, the presented here sol-gel waveguide formation technology is competitive compared to the low pressure chemical vapor deposition (LPCVD) technology. The waveguides presented here may contribute to the development of photonic system technology. 


\section{Summary}

The paper presents sol-gel silica films as well as two-component waveguide layers $\mathrm{SiO}_{2}: \mathrm{TiO}_{2}$ of ultralow attenuation. The elaborated films are good enough to contribute to the development of planar sensors with the application of evanescent field spectroscopy. The porous silica films of low refractive index and low electrical permittivity can be useful in microelectronics. The elaborated waveguide films can contribute to the development of photonic planar systems.

\section{Acknowledgments}

The work is sponsored by the Ministry of Science and High Education within the grant N 515057 31/2432.

\section{References}

[1] C.J. Brinker, G.W. Scherer, Sol-gel Science, Academic Press, San Diego 1990.

[2] P. Karasiński, Opt. Appl. 33, 477 (2003).

[3] P. Karasiński, Opt. Appl. 34, 467 (2004).

[4] P. Karasiński, R. Rogoziński, Opt. Commun. 245, 237 (2005).

[5] P. Karasiński, R. Rogoziński, Opt. Commun. 269, 76 (2007).

[6] P. Karasiński, Opto-Electron. Rev. 15, 168 (2007).

[7] P. Karasiński, R. Rogoziński, Opt. Commun. 281, 2472 (2008)

[8] P. Karasiński, Opt. Appl. 35, 117 (2005).

[9] P. Karasiński, Opt. Appl. 36, 389 (2006).

[10] P. Karasiński, J. Non-Cryst. Solids, submitted for publication. 